\title{
Implementation and evaluation of employee health and wellness program using RE-AIM framework
}

\author{
Unab I. Khan \\ Aga Khan University, unab.khan@aku.edu \\ Asra Qureshi \\ Aga Khan University, asra.qureshi@aku.edu \\ Karishma Lal \\ Aga Khan University \\ Shehreen Ali \\ Aga Khan University, shehreen.ali@aku.edu \\ Arshnoor Barkatalia \\ Aga Khan University, arshnoor.barkatali@aku.edu
}

See next page for additional authors

Follow this and additional works at: https://ecommons.aku.edu/pakistan_fhs_mc_fam_med

Part of the Cardiovascular Diseases Commons, Family Medicine Commons, Nutritional and Metabolic Diseases Commons, Performance Management Commons, and the Training and Development Commons

\section{Recommended Citation}

Khan, U. I., Qureshi, A., Lal, K., Ali, S., Barkatalia, A., Nayani, S. (2021). Implementation and evaluation of employee health and wellness program using RE-AIM framework. International Journal of Workplace Health Management.

Available at: https://ecommons.aku.edu/pakistan_fhs_mc_fam_med/256 


\section{Authors}

Unab I. Khan, Asra Qureshi, Karishma Lal, Shehreen Ali, Arshnoor Barkatalia, and Shamim Nayani 


\section{International Journal of Workplace Health Manag}

\section{Implementation and Evaluation of Employee Health and Wellness Program using RE-AIM framework}

\begin{tabular}{|r|l|}
\hline Journal: & International Journal of Workplace Health Management \\
\hline Manuscript ID & IJWHM-04-2021-0081.R1 \\
\hline Manuscript Type: & Research Paper \\
\hline Keywords: & $\begin{array}{l}\text { RE-AIM framework, Employee Health and Wellness Program, } \\
\text { Framingham risk score (FRS), Metabolic syndrome (MetS), low-middle } \\
\text { income countries, preventive care model }\end{array}$ \\
\hline
\end{tabular}

\section{SCHOLARONE ${ }^{\mathrm{m}}$ Manuscripts}


Implementation and Evaluation of Employee Health and Wellness Program using RE-AIM framework

\section{Authors}

Unab I.Khan ${ }^{\mathrm{a}}$, Asra Qureshi ${ }^{\mathrm{a}}$. Karishma Lal ${ }^{\mathrm{b}}$, Shehreen Ali ${ }^{\mathrm{a}}$, Arshnoor Barkatalia, Shamim Nayanic

a Department of Family Medicine, Aga Khan University Medical College; b Dean's Clinical Research Fellow, Aga Khan University Medical College, ${ }^{\mathrm{c}}$ Department of Human Resources, Aga Khan University, Karachi, Pakistan.

Corresponding Author:

Unab I. Khan MD, MS

Associate Professor

Department of Family Medicine

The Aga Khan University

Stadium Road, P.O Box 3500

Karachi 74800

Pakistan

Tel: +92 2134864842

Fax: +92 2134934294

Funding Sources - No grant funding

Disclosure Statement

The authors listed above hereby certify that they have no conflicts of interest to report.

Acknowledgments: The authors would like to acknowledge the support of the following:

Ms. Carol Ariano, VP-Human Resources; Ms. Samrin Suleman, Manager, Human Resources; Mr. Kashif Siddiqui and Mr. Uzair Danish, Dept. of Software Development and Maintenance; and Employee Health team at Aga Khan Univesity.

Ethical Considerations

The study was approved by the University Ethics Review Committee (ID\# 2019-1281-3520). Written informed consent was obtained from all participants whose data was utilized for research purposes as per ERC guidelines. 


\begin{abstract}
Purpose: To describe the design, implementation, and evaluation of an employer-sponsored health screening program [Employee Health and Wellness Program (EHWP)] in an academic healthcare system in Pakistan.

Design/methodology/approach: One-year after implementation, we use the RE-AIM framework (Reach, Effectiveness, Adoption, Implementation and Maintenance) to evaluate and report participant- and organizational-level indicators of success.
\end{abstract}

Findings: Of 5286 invited employees, 4523 (86\%) completed blood work and 1809 (34\%) completed health risk assessment (Reach). Of the 915 (51\%) who required referrals, 3\% were referred for new diagnoses of diabetes, hepatitis $\mathrm{C}$ or severe anemia; $63 \%$ for elevated 10 year risk of cardiometabolic diseases (cardiovascular disease and diabetes); and 25\% for counseling for depression, obesity or smoking cessation (Effectiveness). Employees' barriers to enrollment were explored (Adoption). While institutional costs were considered nominal (US \$ 20/employee), organizational barriers were identified (Implementation). Finally, 97\% of users reported interest in enrollment if EHWP was offered again (Maintenance).

Originality/ value: In a country with minimal focus on adult preventive care, we report the impact of an employer-offered wellness program that identified new risk factors and offered referral for ongoing care. Employees reported a positive experience and were willing to reenroll. Using the RE-AIM framework, we have defined indicators in the real-world setting, that can be used effectively by other institutions to start such a program.

Keywords: Employee Health and Wellness Program; low-middle income countries; preventive care model, RE-AIM framework; Framingham risk score (FRS); Metabolic syndrome (MetS)

Article classification: Research paper 


\section{INTRODUCTION}

With many adults spending 40-80 hours a week at their place of employment, workplace health initiatives are an opportunity to identify risks, educate employees, and bring change through health-related policies at the organizational level (Glasgow et al., 2001). Wellness programs also improve perceived organizational support and reduce healthcare costs (Gee, 2017). A meta-analysis of workplace wellness programs showed a cost-savings of $\$ 3.27$ in health care costs for every dollar spent (Han, 2019). Similarly, CDC's community guide task force reports a positive impact on biometric measures, health behaviors, and financial outcomes of well-designed workplace wellness programs (Liu et al., 2013). Recent studies suggest that of the various workplace wellness program models, a disease management model offers the most cost-effective approach (Baicker, K. et al., 2010) .

In Pakistan, non-communicable diseases (NCDs) account for $58 \%$ of adult morbidity and mortality (Wasay et al., 2014). One in three adults older than 45 years suffers from hypertension; the prevalence of diabetes is $10 \%$ and it is estimated that $40 \%$ of adults have -5 risk factors of cardiovascular disease (Rafique et al., 2018). In addition, 20\% of adults report using tobacco (Rafique et al., 2018). Nutritional deficiencies are common and 52\% women of reproductive age suffer from iron-deficiency anemia (Global Health Observatory, 2020). With $4-5 \%$ of the population infected, Pakistan also has one of the highest rates of Hepatitis C (Al Kanaani et al., 2018) .

In such a setting, employers have a unique opportunity to play an active role by not only providing medical benefits for treatment of existing diseases but also use workplace wellness 
programs for early identification and treatment of chronic diseases and offer activities that can prevent, reverse or improve the management of NCDs and their associated risk factors. This manuscript describes the creation, implementation and one-year evaluation of a workplace wellness program at a large academic healthcare system in Pakistan.

\section{MATERIALS AND METHODS}

\section{Setting:}

The University is a private, not-for-profit institution established in 1980, with campuses in Pakistan, Kenya, Tanzania and England. This program was offered in Pakistan, where the University has a 710-bed, tertiary-care hospital. In addition, there are four women and child hospitals with 213 beds that provide secondary-level care, 19 medical centers and 310 laboratory facilities in more than 100 cities across the country. In addition, the University includes a Medical College, a School for Nursing and Midwifery, an Institute of Educational Development, and an Examination Board (Aga Khan Development Network, 2021). The University has 12,300 full-time employees across the country, $70 \%$ of whom are engaged in health care.

The University provides medical benefits to all its employees which include highly subsidized inpatient care and a fixed amount for outpatient health services. No monies are specifically assigned for preventive care and screening. An Employee Health Office (Emp Health) assists with pre-employment fitness assessments, preventive immunizations such as Hepatitis B, and monitoring of on-the-job injuries including needlestick exposures.

\section{Design of Employee Health \& Wellness Program (EHWP):}


In 2019, to highlight the importance of preventive health care to its employees, the University launched the Employee Health and Wellness Program (EHWP) as a collaborative between Human Resources and Department of Family Medicine. EHWP focuses on early identification and timely referral for common NCDs including high blood pressure, diabetes, dyslipidemia, and identifies those at high risk of cardiovascular disease and depression. In addition, it screens for anemia and Hepatitis C. Through EHWP, employees obtain free testing, get individual health risk assessment and if required, are referred for further treatment or behavioral counseling. The program is meant for all full-time employees $(12,300)$; and employees would be offered the chance to participate every three years. Thus, the goal was to reach 4500 employees in the first year. Recognizing that there would be a few who may not wish to participate, we reached out to 5286 employees in 40 departments. Of these, 4523 (86\%) completed blood work and 1809 (34\%) completed the health risk assessment. We obtained approval from the Ethics Review Committee (\#2019-1281-3520) for ongoing evaluation of the program at the institutional and participant level.

\section{Implementation of EHWP:}

Human Resources leadership formally announced EHWP to all employees through an internal memo. Department of Marketing and Communications led a campaign using digital standees across campus, internal website, and internal emails. Figure 1 illustrates the steps of EHWP implementation.

- An invitation email is sent to select employees of selected departments, followed by an informational session by the EHWP team. 
- During the informational sessions, time-stamped coupons are distributed for free fasting blood tests. Blood tests include: Hemoglobin $(\mathrm{Hgb})$ and Hematocrit $(\mathrm{HCT})$ to screen for anemia, fasting blood glucose (FBG) for diabetes, fasting lipid profile for dyslipidemia, and a qualitative Hepatitis C RNA test (HCV-PCR).

- $\quad$ Once a critical mass of employees complete their blood tests, EHWP team works with the department administration to arrange individual health risk assessments.

\section{- $\quad$ Health Risk Assessment:}

O The health risk assessment is completed using a specially designed EHWP app (described later).

- At the time of assessment, employees enter personal information including personal medical and family history of NCDs including cardiovascular disease, diabetes, mental health and cancers; behavioral risk factors such as nicotine use (cigarettes and smokeless tobacco) and physical activity. They are also screened for depression by completing the PHQ-2. EHWP nurse helps those who are unable to read/understand English.

○ EHWP nurse measures employees' vital signs and anthropometric measures including waist circumference and documents in the EHWP app.

O With all the required information, the EHWP app uses the Framingham Risk Score (FRS) to assess the 10-year risk of developing cardiovascular disease (Bosomworth, 2011) and ATP-III criteria (Health, 2001) to diagnose metabolic syndrome (MetS).

- At the end of the assessment, EHWP nurse invites employees to participate in the research arm of EHWP. Employees who agree, provide written informed consent. 
Employees who defer still get the complete assessment but are not invited to participate in program evaluation through surveys.

\section{- Referrals}

Employees are referred to a family physician based on the following predetermined criteria: 1) new diagnoses of diabetes, hepatitis $\mathrm{C}$, severe anemia, polycythemia or severe hypertriglyceridemia; 2) those at moderate to high risk of developing cardiovascular disease (FRS $\geq 10$ ) or diabetes (impaired fasting glucose or metabolic syndrome) or elevated blood pressure; and 3) those requiring behavioral interventions for obesity, nicotine addiction, or further evaluation of depression. Employees requiring referral are counseled by the EHWP nurse. Those who already have a primary care physician within the healthcare system are advised to arrange follow-up to discuss results of the health risk assessment.

- Once disposition is decided, the EHWP nurse enters the final decision which marks case closure in the app.

\section{MEASURES:}

\section{- EHWP app:}

The Information Technology (IT) team created an android based app (EHS application ( IP2018 IT) for the sole purpose of collecting EHWP data while maintaining employees' confidentiality. The app is installed on project-specific android tablets that are available only to the EHWP team who can access them through individual user IDs and passwords. The app extracts on-board employees' identity, basic demographics, and department data from the central Human Resources 
database. The EHWP assessment on the app is not part of the employees' medical records, nor is it accessible to administrative personnel or Human Resources.

Individual risk-assessment data are extracted as .xlsx file monthly by EHWP team and transferred directly to research team.

- Referral data: For employees who are referred, an excel sheet is maintained to confirm if they kept the appointment within 3 months of their risk assessment.

- User Survey: To obtain feedback from 10\% of EHWP users, nurses offer a 10-item, paper-based survey to employees who consent to participate in the study. The survey is available in both English and Urdu (local language). For this evaluation, we approached 284 employees of which $186(66 \%)$ responded to the survey. Of these, 49 (26\%) were health care personnel (HCPs), 46 (25\%) were administrative and managerial staff and 91 (49\%) belonged to support departments.

- Non-user survey: We also wanted feedback from $10 \%$ of employees who chose not to participate in EHWP. Nurses contacted employees via telephone or in-person and invited them to complete a 10-item, anonymous, non-user survey. Both English and Urdu versions are available. Of the 763 employees from the select departments who chose not to participate, the team approached 170 employees, of which $93(12 \%)$ completed the non-user survey. Of the non-users, 32 (34\%) were HCPs, 26 (28\%) were administrative and managerial staff and 34 (36.5\%) were from support services.

- Focus-group (FGDs): Two separate FGDs were conducted by the EHWP research team. One was with key stakeholders (leadership from Human Resources and Family 
Medicine) which focused on the rationale for EHWP, vision, barriers and challenges and willingness to continue the program. The second FGD was with the EHWP team on implementation challenges.

\section{PROGRAM EVALUATION:}

We used the RE-AIM framework to evaluate the program. RE-AIM's five domains (Reach, Effectiveness, Adoption, Implementation and Maintenance) have been used to evaluate impact of both clinical and community-based interventions, including interventions targeting disease management (Glasgow et al., 2001; Shaw et al., 2019). RE-AIM allows a shift from short-term efficacy in restricted research studies to longer-term effectiveness in the realworld setting.

\section{Operationalization of RE-AIM Domains:}

Measures used to examine each domain are summarized in Table 1. Reach:

We documented the participation rate within the pre-defined target for the year from all fulltime employees. To understand factors that could affect reach, we used select items from the non-user survey to examine awareness of the program and its purpose, and compared differences between the three groups of employees.

\section{Effectiveness:}

We evaluated the impact of EHWP on the organizational level by measuring the number of employees who were referred for one or more of the target outcomes and those who kept their appointments within three months of the health risk assessment.

\section{Adoption:}


To assess adoption at the participant level, we used specific questions from the user and nonuser surveys and compared responses among employee groups. Ease of getting blood tests and individual risk assessments, and concerns about confidentiality and cost were evaluated in both users and non-users.

\section{Implementation:}

We evaluated implementation at the organizational level by examining the consistency of EHWP with its stated mission, by using 1) the stakeholder FGD to assess administrative and organizational support; and 2) FGD with EHWP team to explore the resources and expertise required, and the perceived support and barriers to implementation.

\section{Maintenance:}

At the organizational level, we assessed the perceived benefit and willingness to continue funding the program during the leadership FGD.

At the participant level, we used questions from the user survey that assessed: employees' satisfaction and perception of usefulness of EHWP, willingness to recommend the program to colleagues and participate in the program were it to be offered again. In addition, lack of interest in participation was assessed from non-user survey.

\footnotetext{
ANALYSIS

We used descriptive statistics for each domain of RE-AIM. Data from the user survey and non-user survey groups were analyzed separately. All survey participants were categorized into three employment categories, 1) Health Care Personnel (HCPs) (employees involved in direct patient care); Administrative Staff (employees in managerial roles and those who facilitate institutional processes); and Support Staff (employees involved in managing services and facilities). Differences of agreement to responses between three groups were examined using Kruskal Wallis rank test. All analyses were conducted using Stata $15.0^{\circledR}$.
} 
For both FGDs, manual thematic content analysis (Burnard et al., 2008) was performed. FGDs were transcribed verbatim by EHWP research team, themes were coded individually by two members of the research team. Common themes were identified, and a final coding framework was created.

\section{RESULTS}

Table 3 explains the different questions from the user and non-user survey that are used for each domain of RE-AIM.

\section{Reach}

Figure 1 shows the reach of the program. From March 2019 to March 2020, 5286 employees from 40 departments were invited to participate in the program. Of these, $4523(85.6 \%)$ performed their fasting blood work; and 1809 (34\%) completed their individual risk assessments. The goal was to reach 4500 employees in the first year, and while we were able to complete blood work on the assigned numbers, we had to stop individual risk assessments in March 2020 as EHWP team became involved in COVID-19 screening for employees. In the non-user survey, as compared to support services staff, a larger proportion of HCPs and administrative staff reported that they were unaware of EHWP (3\% of support staff vs. $19 \%$ HCPs vs. $23 \%$ administrative staff. However, the difference was not statistically significant. (Kruskall Wallis $\chi^{2}: 2.41 ;$ p-value:0.3) (Table 3). In addition, $42 \%$ of employees completing the non-user survey stated that they were unclear about the purpose of program with no difference among the groups.

\section{Effectiveness:}


Of the 1809 (34\%) employees who completed the individual risk assessments, 915 (51\%) needed further medical care based on the referral criteria given in Table 2. Of those referred, $313(34 \%)$ kept their referral appointment. It was noted that a higher proportion of employees kept appointments when diagnosed with diseases such as diabetes (48\%), hepatitis C (62\%) or anemia (33\%); whereas the lowest follow up rates were noted where lifestyle modification such as counseling for obesity (6\%) and smoking cessation (25\%) were suggested.

\section{Adoption:}

At the participant level, $98 \%$ of users felt the process of getting lab testing was easy; $97 \%$ stated that making the appointment for individual risk-assessment was easy; and $92 \%$ felt the wait time was acceptable. There was no significant difference in level of agreement among HCPs, administrative and support staff. In contrast, among the non-users, $48 \%$ stated that they were unable to get the lab testing completed on time; and $47 \%$ stated that they did not get the time to get their individual risk assessments. (Table 3) In addition, $21 \%$ of non-users were unclear as to who would pay for program participation.

To ensure that confidentiality and privacy were not barriers to adoption, we asked the same question of both users and non-users. $99 \%$ of users responded that they felt assured that their results would be kept confidential by EHWP team, with no significant difference among employee categories. Of the non-users, a higher proportion of HCPs were concerned about confidentiality of medical information compared to the other two employee categories, but the difference was not statistically significant (HCP: $22 \%$ vs. administrative staff $15.4 \%$ vs. support staff 3\%; $\chi^{2}: 2 ;$-value: 0.35 ) (Table 3 ).

\section{Implementation:}


We used the two focus group discussions to assess implementation at the organizational level. The leadership FGD included five members: three from Human Resources and two from Family Medicine where Employee Health sits. It assessed administrative and institutional support as well as expected barriers. The FGD with the EHWP team (two nurses and two health care assistants) explored the resources required and the support and barriers to implementation. Key stakeholders in Human Resources and Family Medicine noted strong Institutional support for the program. They considered EHWP as an important component of the institutional vision of a healthy workplace environment. The cost of PKR 3000/employee (USD 20/employee) was considered feasible. Another theme that emerged was access to quality health care for employees to decrease absenteeism and effective utilization of medical benefits. Other reasons included moving towards preventable care and early detection of diseases; creating awareness and changing perceptions about mental distress; and empowering employees to take control of their own health. One member said, "We are a healthcare organization. The University provides health facilities, but our staff should know how to keep themselves healthy too".

The FGD with the EHWP team explored the resources required and the support and barriers to implementation. They shared the difficulty in engaging with employees, particularly support staff for whom the concept of preventive care was new. One nurse said, "Many people said to just give them the money and they will decide what to spend it on. It took time to explain why these tests were important for their health". Awareness sessions were effective in improving reach of the program. Another challenge was of supervisors' reluctance to grant time for blood work and individual risk assessments. In departments where there was active involvement of management, the engagement and participation was much higher. EWHP team also noted resource constraints as no additional staff was hired to run the program. This led to delays in offering in-person assessments soon after the lab tests 
were performed, which led to employees seeking consults from other physicians at the institution by using their own medical benefits. One member said, "We had to do this along with all our other work. Maybe some money should have been kept for additional staffing to help run the program."

\section{Maintenance}

At the organizational level, in FGDs with both stakeholders and EHWP team, there was unanimous agreement that EHWP was a necessary and successful program. Human Resources team was proud of the Institution setting a precedent of improving care of its employees in Pakistan and felt that it could become a model program for other organizations to follow. One member mentioned, "our Institution always leads in workplace safety. By adding this program, we are showing the institutional commitment to employees ' health."

At the participant level, of employees who answered the questionnaire, $98 \%$ were satisfied with the program; and $97 \%$ reported that they would participate in the program when it is offered again (Table 3).

From the non-user survey, we used two questions to understand the likelihood of employees' participation. $27 \%$ of employees mentioned that they already had a primary care physician and were thus uninterested in joining the program. Interestingly, $6 \%$ of $\mathrm{HCPs}, 8 \%$ of administrative staff and $12 \%$ of support staff reported that they were not interested in finding their health status. Again, there was no statistical difference in the response between the three groups.

\section{DISCUSSION}


In a country where no health care resources are allocated for adult preventive care, employee wellness programs can play a substantial role in early identification and referral to care for common NCDs (including mental health) and chronic infections. In this evaluation of the first year of Employee Health and Wellness Program (EHWP), we show evidence of employee engagement and identification of new risk factors, which if treated, can lead to long-term improvement in health and well-being of employees, and significant cost-savings for the Institution. Using the REAIM framework, we have defined indicators in the realworld setting, which can now be used by other institutions in low-income countries.

Health screening models not only show positive benefits by identifying health-related risk factors, but are also correlated with employees' commitment to institution (Goetzel et al., 2014). With an $85 \%$ participation rate in blood tests, employees have shown an interest in learning more about their health if it does not entail use of their own resources. However, it is also important to explore the reasons for the $15 \%$ who chose not to participate. We found that $42 \%$ of the non-users stated that they were unclear about the purpose of EHWP. Ongoing trust-building within the institution and clear communication of the purpose of the program thus become extremely important.

While our program completion rates are similar to other workplace wellness programs in academic medical institutions in the first year of implementation (Glasgow et al., 2001), we did have a significant drop in participation from blood tests $(85 \%)$ to individual risk assessments (34\%). Specific questions in the user and non-user surveys addressing adoption of the program provide some understanding of these results. While 97\% of EHWP users reported ease in getting blood work and individual risk assessments, $48 \%$ of non-users identified time as a major barrier in EHWP participation. Thus, working with departmental leadership to allocate time could enhance participation (Hoert et al., 2018). 
At the organizational level, implementation barriers were highlighted by the EHWP team during FGD. The limited resources led to decreased availability of appointments for individual risk assessments. Our investment was minimal (US \$20/employee), which was mostly spent on cost of blood work. Initiating workplace wellness programs without adequate resources could lead to potential failures (Baicker, Katherine et al., 2010).

Despite our inability to complete assessments on all the employees we had hoped to target, the effectiveness of EHWP cannot be denied. Of those who completed assessments, $51 \%$ were identified to either have new diagnoses such as diabetes $(1.8 \%)$, severe anemia $(0.5 \%)$ or hepatitis $\mathrm{C}(1.6 \%)$; or have medical conditions that increase their 10 -year risk of cardiovascular morbidity and mortality (elevated BP: $3.4 \%$; FRS $\geq 10: 15.5 \%$; or (MetS: 37.7\%). During subsequent cycles, we will evaluate longitudinal changes in cardiometabolic risk factors with linkage to care. We also noted lower follow-up rates for conditions requiring behavioral modification such as obesity and nicotine addiction. Health risk assessments complemented by behavioral interventions are more likely to be successful (Addley et al., 2014). In addition, other workplace wellness programs suggest the importance of mental health support in employee wellbeing (Dickson-Swift et al., 2014). Thus, there is a need to expand EHWP and include behavioral interventions from the same platform as a part of a coordinated chronic disease care approach.

Adoption of a new program is always a challenge. In a health care setting where supervisors may have ready access to medical records, trust of employees that their health information will be kept confidential and private is extremely important. The EHWP team spent significant time during orientation sessions to discuss the mechanisms by which confidentiality would be maintained (e.g., creation of an EHWP app). It was reassuring to see that $99 \%$ of the users were satisfied with the privacy of the setting where the health care 
assessments took place; and were secure about the confidentiality of their medical information. This trust in the confidentiality of EHWP was noted across the different cadres of employees, including health-care personnel. In addition, only a small percentage of nonusers $(14 \%)$ cited concerns of confidentiality as the reason to not use the program. This trust in EHWP gives us more confidence in the ongoing success of the program.

While we were unable to find reports of similar workplace wellness programs in Pakistan to compare EHWP, the RE-AIM framework can allow similar indicators to be used by others in program evaluation.

Several elements were critical in the successful launch of EHWP: strong leadership support, need for minimal extra financial expenditure by the Institution, use of existing employee health office resources, implementation of specific strategies and timely evaluation of the program. Even for those who have not completed their individual assessments, the general awareness of the need of preventive care adds to the goal that we wanted to achieve. Pakistan's health budget allocates $\$ 45$ per capita for health; of which the government only spends $\$ 14$ on each citizen annually and \$28 is out-of-pocket health expenditure (Mirza, 2021). In a country with limited monies allocated to healthcare, with no focus on adult preventive care, our program shows the significant impact of an employee wellness program. The institutional commitment will allow us to continue to focus and in time expand the services through EHWP and improve the risk factor profile of the employees. 


\section{References:}

ADDLEY, K. et al. The impact of two workplace-based health risk appraisal interventions on employee lifestyle parameters, mental health and work ability: results of a randomized controlled trial. Health education research, v. 29, n. 2, p. 247-258, 2014. ISSN 1465-3648.

Aga Khan Development Network. 3-15-2021 2021. https://www.akdn.org/our-agencies/agakhan-university/university-hospitals-network. Accessed on: 4-1-2021.

AL KANAANI, Z. et al. The epidemiology of hepatitis $C$ virus in Pakistan: systematic review and meta-analyses. Royal Society open science, v. 5, n. 4, p. 180257, 2018. ISSN 20545703.

BAICKER, K.; CUTLER, D.; SONG, Z. Workplace wellness programs can generate savings. Health Affairs, v. 29, n. 2, p. 304-11, Feb 2010. ISSN 1544-5208.

BAICKER, K.; CUTLER, D.; SONG, Z. Workplace wellness programs can generate savings. Health affairs, v. 29, n. 2, p. 304-311, 2010. ISSN 0278-2715.

BOSOMWORTH, N. J. Practical use of the Framingham risk score in primary prevention: Canadian perspective. Canadian Family Physician, v. 57, n. 4, p. 417-423, 2011. ISSN 0008-350X.

BURNARD, P. et al. Analysing and presenting qualitative data. British dental journal, v. 204, n. 8, p. 429-432, 2008. ISSN 1476-5373.

DICKSON-SWIFT, V. et al. What really improves employee health and wellbeing: Findings from regional Australian workplaces. International Journal of Workplace Health Management, 2014. ISSN 1753-8351.

GEE, L. M. Employee wellness program attitudes. 2017. 32 Honors Program Thesis (Honors Program Thesis). Psychology, University of Northern lowa, UNI scholar works.

GLASGOW, R. E. et al. The RE-AIM framework for evaluating interventions: what can it tell us about approaches to chronic illness management? Patient education and counseling, v. 44, n. 2, p. 119-127, 2001. ISSN 0738-3991.

GLOBAL HEALTH OBSERVATORY, W. Nutrition Landscape Information System 2020.

GOETZEL, R. Z. P. et al. Do Workplace Health Promotion (Wellness) Programs Work? Journal of Occupational \& Environmental Medicine, v. 56, n. 9, p. 927-934, 2014. ISSN 1076-2752.

HAN, M. Participation and Effectiveness of Worksite Health Promotion Program. 2019. (Ph.D.). Nursing, University of Maryland, Baltimore

HEALTH, N. I. O. ATP III guidelines at-a-glance quick desk reference. NIH publication, p. 013305, 2001.

HOERT, J.; HERD, A. M.; HAMBRICK, M. The role of leadership support for health promotion in employee wellness program participation, perceived job stress, and health behaviors. American Journal of Health Promotion, v. 32, n. 4, p. 1054-1061, 2018. ISSN 0890-1171. 
LIU, $H$. et al. Effect of an employer-sponsored health and wellness program on medical cost and utilization. Population Health Management, v. 16, n. 1, p. 1-6, Feb 2013. ISSN 19427905.

MIRZA, Z. Healthcare and Budget 2021-22. DAWN. Pakistan: DAWN 2021.

RAFIQUE, I. et al. Prevalence of risk factors for noncommunicable diseases in adults: key findings from the Pakistan STEPS survey. East Mediterr Health J, v. 24, n. 1, p. 33-41, 2018.

SHAW, R. B. et al. Operationalizing the reach, effectiveness, adoption, implementation, maintenance (RE-AIM) framework to evaluate the collective impact of autonomous community programs that promote health and well-being. BMC public health, v. 19, n. 1, p. 803, 2019. ISSN 1471-2458.

WASAY, M.; ZAIDI, S.; JOOMA, R. Non communicable diseases in Pakistan: burden, challenges and way forward for health care authorities. Journal of Pakistan Medical Association, v. 64, n. 11, p. 1218-1219, 2014. 
Figure I- Reach of Employee Health \& Wellness Program

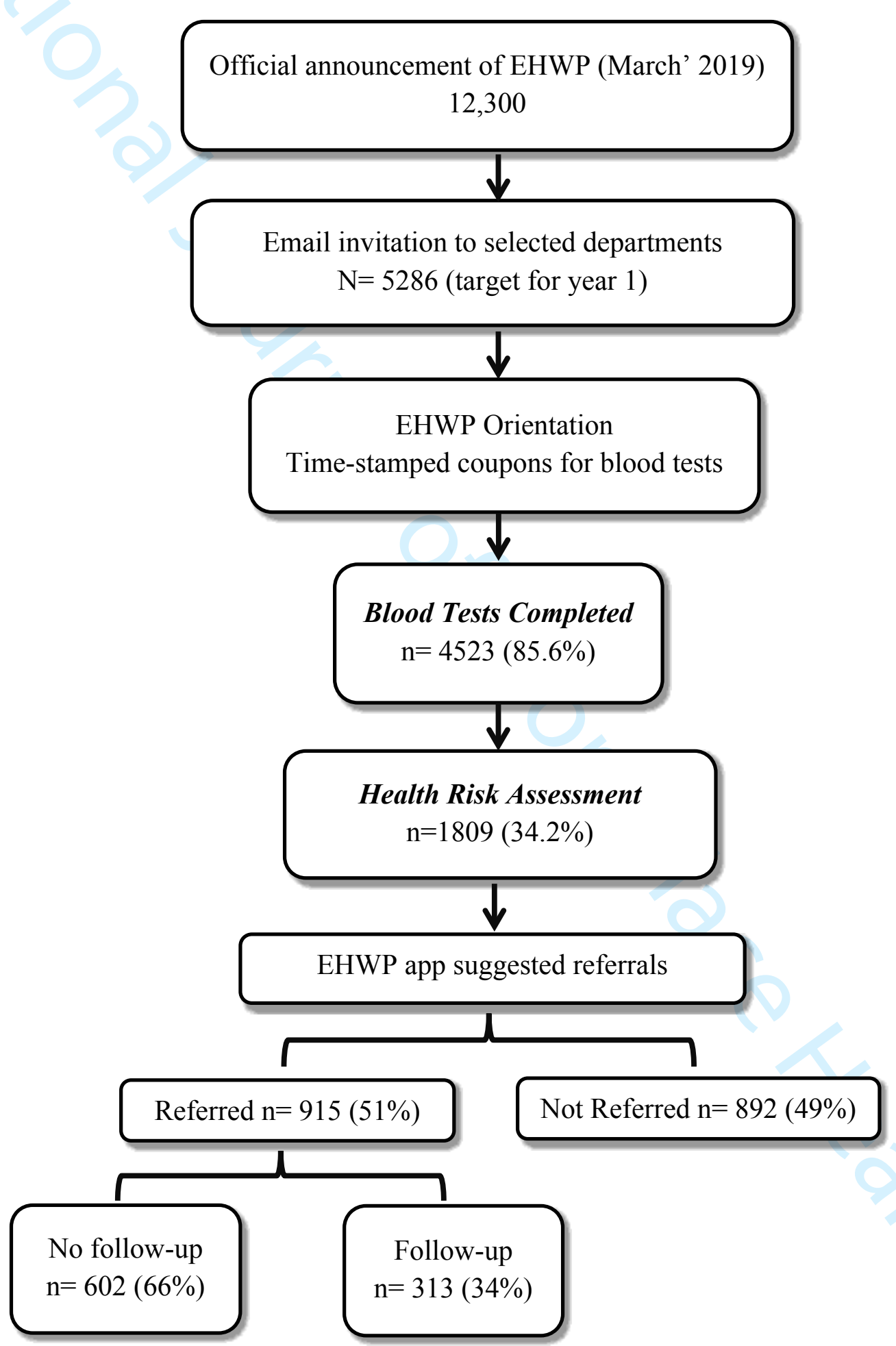


Table I- Measures of RE-AIM Domains

\begin{tabular}{|c|c|c|}
\hline DOMAINS & MEASURES & METHODS \\
\hline Reach & Organizational level & \\
\hline 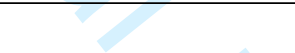 & - Number of employees invited & Initial numbers \\
\hline & - Proportion of employees completing lab tests & EHWP App \\
\hline & $\begin{array}{l}\text { Proportion of employees completing health } \\
\text { risk assessments }\end{array}$ & EHWP App \\
\hline & - Awareness of EHWP & Non-user survey \\
\hline & - Awareness of purpose of EHWP & Non-user survey \\
\hline \multirow[t]{2}{*}{ Effectiveness } & Organizational level & \\
\hline & $\begin{array}{l}\text { Proportion of employees identified with new } \\
\text { diagnoses and requiring referral }\end{array}$ & $\begin{array}{l}\text { EHWP App \& Referral } \\
\text { sheet }\end{array}$ \\
\hline \multirow[t]{6}{*}{ Adoption } & Participant level & \\
\hline & $\begin{array}{l}\text { - Ease of process (getting lab tests and risk } \\
\text { assessments) }\end{array}$ & User survey \\
\hline & - Acceptability of wait-time & User survey \\
\hline & - Time to get lab tests and risk assessments & Non-user survey \\
\hline & - Confidentiality of health information & $\begin{array}{l}\text { User and Non-user } \\
\text { surveys }\end{array}$ \\
\hline & - Concerns about cost of enrollment & Non-user survey \\
\hline \multirow[t]{3}{*}{ Implementation } & Organizational level & \\
\hline & - Institutional support & Leadership FGD \\
\hline & - Support and Barriers in implementation & EHWP team FGD \\
\hline \multirow[t]{9}{*}{ Maintenance } & Organizational level & \\
\hline & - Necessity and willingness to continue & Leadership FGD \\
\hline & Participant level & \\
\hline & - Satisfaction with EHWP & User survey \\
\hline & - Usefulness of EHWP & User survey \\
\hline & - Likelihood of following recommendations & User survey \\
\hline & - Likelihood of re-enrollment if offered again & User survey \\
\hline & - Likelihood of recommending to a colleague & User survey \\
\hline & - Lack of interest in participation & Non-user survey \\
\hline
\end{tabular}


Table II- Effectiveness of Employee Health and Wellness Program

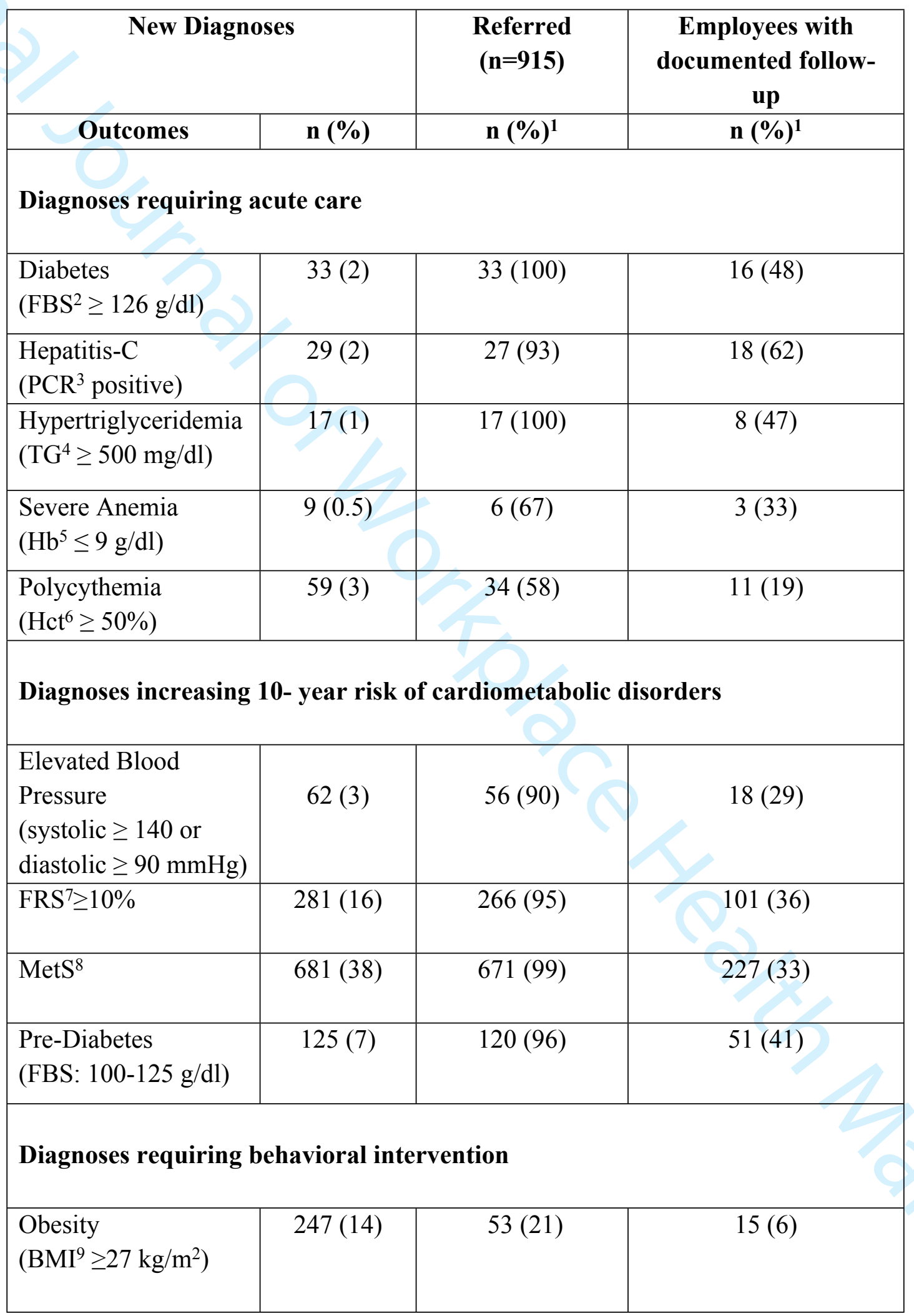




\begin{tabular}{|l|c|c|c|}
\hline Tobacco use & \\
& $271(15)$ & $114(42)$ & $37(14)$ \\
\hline PHQ-2 ${ }^{11}$ positive & $43(2.3)$ & $43(100)$ & $19(44)$ \\
\hline
\end{tabular}

${ }^{1}$ Denominator for each percentage is the number of positive cases for that particular outcome; ${ }^{2}$ Fasting Blood Sugar; ${ }^{3}$ Polymerase Chain Reaction; ${ }^{4}$ Triglycerides; ${ }^{5}$ Hemoglobin; ${ }^{6}$ Hematocrit ${ }^{7}$ Framingham Risk Score; ${ }^{8}$ Metabolic Syndrome; ${ }^{9}$ Body Mass Index (National Health Survey Pakistan 1990-1994); ${ }^{10}$ Out of 271 people who reported using tobacco, 114 wanted to quit and were referred.

${ }^{11}$ Patient Health Questionnaire-2 
Table III: Differences in responses on user and non-user survey among employee groups

\begin{tabular}{|c|c|c|c|c|c|c|}
\hline & $\mathbf{N}(\%)$ & $\begin{array}{l}\text { HCPs } \\
\text { n(\%) }\end{array}$ & $\underset{\mathrm{n}(\%)}{\operatorname{Admin}^{2}}$ & $\begin{array}{c}\text { Suppor } \\
\mathbf{t}^{\mathbf{3}} \\
\mathbf{n}(\%) \\
\end{array}$ & $\chi^{4}$ & p-value \\
\hline \multicolumn{7}{|l|}{ REACH } \\
\hline \multicolumn{7}{|l|}{ Non-users } \\
\hline Not aware of EHWP & $14(15)$ & $6(19)$ & $6(23)$ & 1(3) & 2.4 & 0.30 \\
\hline Not clear for EHWP purpose & $39(42)$ & $7(22)$ & 9(34) & $12(35)$ & 0.7 & 0.69 \\
\hline & $20(21)$ & $8(25)$ & $6(23)$ & $5(15)$ & 0.7 & 0.70 \\
\hline \multicolumn{7}{|l|}{ ADOPTION } \\
\hline \multicolumn{7}{|l|}{ Users } \\
\hline Lab tests process was easy & $177(98)$ & $46(96)$ & $43(95)$ & $88(100)$ & 0.2 & 0.88 \\
\hline $\begin{array}{l}\text { Appointment for nurse assessment was } \\
\text { easy }\end{array}$ & $179(97)$ & $47(96)$ & $46(100)$ & $86(96)$ & 0.1 & 0.93 \\
\hline Waiting acceptable & $154(92)$ & $43(98)$ & $36(90)$ & $75(90)$ & 0.5 & 0.76 \\
\hline Assessments conducted under privacy & $183(99)$ & $46(96)$ & $46(100)$ & $91(100)$ & 0.1 & 0.91 \\
\hline Assured for results confidentiality & $180(99)$ & $48(98)$ & $44(100)$ & $88(99)$ & 0.0 & 0.98 \\
\hline \multicolumn{7}{|l|}{ Non-users } \\
\hline Could not get lab work on time & $45(48)$ & $14(44)$ & $10(38)$ & $20(59)$ & 2.0 & 0.36 \\
\hline Did not get time for nurse assessment & $44(47)$ & $15(47)$ & $10(38)$ & $18(53)$ & 0.5 & 0.74 \\
\hline $\begin{array}{l}\text { Not assured for medical information } \\
\text { confidentiality }\end{array}$ & $13(14)$ & $7(22)$ & $4(15)$ & $1(3)$ & 2.0 & 0.35 \\
\hline \multicolumn{7}{|l|}{ MAINTENANCE } \\
\hline \multicolumn{7}{|l|}{ Users } \\
\hline $\begin{array}{l}\text { Nurse assessment provided useful health } \\
\text { information }\end{array}$ & $180(99)$ & $47(98)$ & $46(100)$ & $87(99)$ & 0.03 & 0.98 \\
\hline Plan to follow recommendations & 172(99) & $43(95)$ & $42(100)$ & $87(99)$ & 0.1 & 0.91 \\
\hline $\begin{array}{l}\text { Likely to recommend EHWP to } \\
\text { colleagues }\end{array}$ & $175(99)$ & $44(96)$ & $43(100)$ & $88(100)$ & 0.1 & 0.90 \\
\hline Likely to return for a second assessment & $178(97)$ & $45(96)$ & $44(95)$ & $89(98)$ & 0.06 & 0.97 \\
\hline
\end{tabular}


3

4

6

8

9

10
11

12

13

14

15

16

17

\begin{tabular}{|l|c|c|c|c|c|c|c|}
\hline & & & & & & \\
\hline Overall satisfaction & $181(98)$ & $48(98)$ & $44(100)$ & $89(98)$ & 0.05 & 0.98 \\
\hline Non-Users & Already in consultation with doctor & $25(27)$ & $8(25)$ & $9(34)$ & $8(23)$ & 0.4 & 0.79 \\
\hline & Not interested in my health findings & $9(10)$ & $2(6)$ & $2(8)$ & $4(12)$ & 0.1 & 0.92 \\
\hline
\end{tabular}

${ }^{1}$ Health care providers from clinical areas [Users 49, Non-users 32]

${ }^{2}$ Administrative, managerial staff [Users 46, Non-users 26]

${ }^{3}$ Support services [facilities, maintenance and nutrition] [Users 91, Non-users 34]

${ }^{4}$ Kruskal-Wallis equality-of-populations rank test 